\title{
Development of an Extended Measure of Work-Life Balance: An Empirical Study with Reference to IT Industry
}

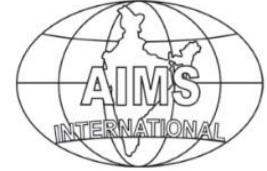

DOI: $10.26573 / 2017.11 .3 .3$

Volume 11, Number 3

September 2017, pp. 191-206

\author{
Vidyavathi Manupadu \\ Surendra Prasad \\ Osmania University \\ (vidyavathim1002@gmail.com) \\ (dr.surendra28@gmail.com)
}

Work Life balance Culture (WLC) measures the perception of the employees about the organizations' support for Work-Life Balance (WLB). The present work proposes to develop an extended measure of WLB by adding WLC as a new dimension to the study and measurement of WLB. The existing works do not take WLC into consideration while developing measurement scales for WLB. A scale consisting of 35 statements has been developed for WLB measurement and the employees of IT organizations of South India were chosen for the study. Dimensions (factors) were resolved through factor analysis, and Pearson correlation analysis and Regression analysis were used to test the hypotheses. By adding WLC as a new dimension, the present study revealed additional factors which affect $W L B$ besides the factors established through earlier works.

Keywords: Work-Life Balance, Work-Life Balance Culture, IT Organizations, Factor Analysis, Regression Analysis

\section{Introduction}

IT organisations have introduced flexible working schedules and work from home option to their employees to help them maintain Work-Life Balance (WLB). WLB is the ability to experience a sense of control and to stay productive and competitive at work, while maintaining a happy and healthy home life with sufficient leisure. It encompasses everything that is required to lead healthy \& satisfactory personal life and also a productive \& progressive work life.

\subsection{Meaning of WLB}

Kirchmeyer (2000) views living a balanced life as "achieving satisfying experiences in all life domains, and to do so requires personal resources such as energy, time, and commitment to be well distributed across domains'". Clark (2000) defines workfamily balance as "satisfaction and good functioning at work and at home with a minimum of role conflict', According to Fisher (2001), WLB is a multidimensional construct, and work interferes with personal life and personal life interference with work, and work enhancement occurs with personal life/ Personal life enhancement occurs with work. Work and family are interdependent domains and problems 
occurring in the one domain could affect other domain. Enhancement in one domain may enrich the other also.

\subsection{Meaning of WLC}

Thompson et al., (1999) define work-family culture as "the shared assumptions, beliefs, and values regarding the extent to which an organization supports and values the integration of employees' work and family lives". Work-family culture is different from work-family balance as it assesses the perception of the individuals towards organisations' support for work-family balance. As described by Bradley et al., (2010), it would be appropriate to substitute 'family' in work-family culture with 'life' to include all the non-work aspects of an individuals' life. This substitution will also enable studying the WLC of individuals who do not have families. Based on the existing literature, the support from the organisation is crucial for bridging the gap between the policy provision and utilization of the policies. Hence it is pertinent to study the cultural aspects of the organizations which influence WLB.

The present study envisages studying Work-life balance, by adding WLC as a new dimension, among the employees of IT sector in South India.

\subsection{Literature Review}

Clark (2000) introduces work/family border theory - a new theory about work/family balance according to which, people are daily border-crossers between the domains of work and family. Kofodimos (1993) suggests that imbalance arouses high levels of stress, detracts from quality of life, and ultimately reduces individual's effectiveness at work. Greenhaus \& Powell (2006) proposed a theoretical model of work-family enrichment and offered a series of research propositions that reflect two paths to enrichment: an instrumental path and an affective path. Greenhaus et al. (2003) identified three components to measure work-family balance namely, time, involvement, and satisfaction. Gropel \& Kuhl (2009), state that there is a direct relationship between satisfaction at work and social domains, and work life balance and subjective well-being.

Edvardsson \& Gustavsson (2003) believe that enough attention has not been towards working conditions of service inclined employees despite understanding the relationship between wellbeing of the employees and success of the organisation. Mark \& MacDermid (1996) found that people who maintain more balance across their entire systems of roles and activities will score lower on measures of role strain and depression and higher on measures of well-being. Zedeck (1992) discusses the importance of studying work and family issues in the research, public, and organizational domains, and argues that industrial and organizational psychologists need to focus more on issues and problems within the work and family domain. Mathew \& Panchanatham (2010) examined the relationships of various facets of work-family balance with organisational commitment, and its various dimensions among employees working in the service sector in India. Mathew \& Panchanatham (2010) developed a forty two items four factor instrument for measuring the WLB of employees working in the service sector. Milind \& Rajashree (2014) analyzed the work-life balance situation of the Indian hotel employees and its impact on employee productivity. The major objective of the study by Rincy \& Panchanatham (2011) was to develop and validate an appropriate tool to illustrate the WLB issues faced by women entrepreneurs of South India. The study by Jyothi \& 
Jyothi (2012) focused on the relationship between role efficacy and emotional intelligence as related to WLB of Career women in a southern state of India.

Thompson et al. (1999) showed that culture was an important concept that was related to work attitudes above and beyond what is accounted for by the availability of flexible work arrangements. According to Allen (2001), Greenhaus \& Parasuraman (1994) and Thiede \& Ganster (1995), the use of organizational worklife programs provides a number of individual and organizational benefits including the reduction of work-family conflict. Baltes et al. (1999) reported reduction in absenteeism and turnover intention due to organisational support. Frone et al. (1997), Konrad \& Mangel (2000), state that improved life satisfaction, well-being, higher organizational performance and productivity were found to be products of positive organizational environment.

Bradley et al. (2010) have extended and added two more dimensions to the existing work done by Thompson et al. (1999) and Behson (2002) studied the impact of the organizational context related to work-family culture compared with the impact of broader perceived organizational support. Frone et al. (1997) found that a supportive work-life culture in terms of work-time commitment reduces work-family conflict. Rothausen (1994) and Solomon (1994) found that improved job satisfaction and increase in productivity were direct results of supportive work atmosphere.

A study by Allen \& Russell (1999) reported that employees were rewarded less compared to those who did not utilize family-friendly policies. Greenhaus et al. (2003) examined the relation between work-family balance and quality of life among professionals employed in public accounting. It was found that individuals who spent more time on family than work experienced a higher quality of life than balanced individuals who, in turn, experienced a higher quality of life than those who spent more time on work than family.

Hall (1990) proposed an organization-change approach to promoting work-family balance. An examination of the literature on conflict between work and family roles suggests that work-family conflict exists when: (a) time devoted to the requirements of one role makes it difficult to fulfil requirements of another; (b) strain from participation in one role makes it difficult to fulfil requirements of another; and (c) specific behaviours required by one role make it difficult to fulfil the requirements of another as stated by Greenhaus \& Beutell (1985).

A study conducted by Perry-Smith \& Blum (2000) suggests that organizations with more extensive work-family policies have higher perceived firm-level performance. The study conducted by Greenhaus, Parasuraman \& Collins (2001) extended prior analyses by Greenhaus et al. (1997) by examining relationships between two directions of work-family conflict (work-to-family conflict and familyto-work conflict) and withdrawal intentions from public accounting. It was found that work-to-family conflict (but not family-to-work conflict) was positively related to withdrawal intentions. Netemeyer et al. (1996) reported on a 3-sample study that developed and validated short, self-report scales of work-family conflict (WFC) and family-work conflict (FWC).

Two new dimensions: Gender expectations and Co-worker support for measuring work-family balance culture were first proposed by McDonald et al. (2005) as explanations for why work-life balance policy usage was low. Ashwini \& Anand (2014) conducted a study on quality of work-life in which eight factors were examined to establish the relationship with the same. Sussanna \& Rashad (2014) 
investigated the relationship between flexible working hours and WLB. Susi \& Jawaharrani (2011) examined the WLB policies followed in industries to increase employee engagement and it was found that there were positive outcomes on employee commitment due to family friendly policies.

\section{Research Methodology}

\subsection{Research Gap \& Objectives}

In the literature, extensive discussion and study of WLB is available. The work/studies conducted by Kofodimos (1993), Kirchmeyer (2000), Clark (2000), Fisher (2001) and Greenhaus et al. (2003) defined WLB, analysed its dimensions, proposed measurement scales and assessed its relation with various dimensions like quality of work life. The studies conducted by Mathew \& Panchanathan (2010) in Indian context, developed measurement scale for WLB and analysed its impact on organisational commitment. Study of WLB in Indian IT sector was limited to a city in particular by Rashida Banu \& Duraipandian (2014) and Chandrasekar et al. (2013). These studies did not capture the general trend in implementation of WLB practices in IT sector across South India and the employee perception on the same. Moreover, the existing studies do not include WLC in the study of WLB. Hence, an extended measure of WLB taking the work life cultural aspects into consideration is being proposed. Though some work is reported by Thompson et al. (1999) and Bradley et al. (2010), but not in the Indian context.

The present work undertaken addresses this gap and envisages studying and measuring the Work-Life balance of employees of IT industry in South India by adding a new dimension: WLC. Specifically, the aim of the study is to (a) develop a measurement tool for WLB, (b) determine the factors affecting the WLB, and (c) study the relation between WLB and WLC.

Based on the extensive literature review, the following hypotheses are formulated:

\section{First Hypothesis}

Null Hypothesis $\mathbf{H}_{10}$ : Work-Life Balance has no significant relationship with WorkLife balance Culture.

Alternate Hypothesis $\mathrm{H}_{1 \mathrm{a}}$ : Work-Life Balance has significant relationship with Work-Life balance Culture.

\section{Second Hypothesis}

Null Hypothesis $\mathbf{H}_{20}$ : Personal life interference in work life and interference of work in personal life are not related to Work-Life Balance.

Alternate Hypothesis $\mathrm{H}_{2 \mathrm{a}}$ : Personal life interference in work life and interference of work in personal life are related to Work-Life Balance.

\section{Third Hypothesis}

Null Hypothesis $\mathbf{H}_{\mathbf{3 0}}$ : Work improvement by personal life and personal life improvement by work have no significant influence on Work-Life Balance.

Alternate Hypothesis $\mathrm{H}_{3 \mathrm{a}}$ : Work improvement by personal life and personal life improvement by work have significant influence on Work-Life Balance.

\subsection{Conceptual Model for Development of Scale}

To measure the WLB, by adding WLC as a new dimension, of the employees of IT industry in South India, open ended questions and informal semi structured 
interviews were used. Based on the personal interactions and qualitative research, a questionnaire of 37 statements was prepared to assess WLB. The preparation of the statements was largely influenced by the work reported in Fisher-McAuley et al. (2003), Greenhaus et al. (2003), Hayman (2005), Mathew \& Panchanathan (2010), Thompson et al. (1999) and Bradley et al. (2010).

Finally, the questionnaire consisted of two parts: (i) 10 statements to determine the demographic profile of the participants and (ii) 37 statements to assess WLB. The second part of the questionnaire employed five point Likert's scale ranging from Strongly Disagree, Disagree, Neutral, Agree and Strongly Agree for obtaining the responses. As a pre-test, the questionnaire was administered to 40 employees of IT organisations before going for the actual data collection. The employees were comfortable in answering the questionnaire and the data provided in the pre-test had some agreement with the findings of Thompson et al. (1999), Bradley et al. (2010), and Fisher (2001).

\subsection{Data Collection}

Data required for the present study was collected through Survey method from a sample population consisting of employees of various IT organisations in South India. The cities covered in this study are: Hyderabad, Chennai, Bangalore, Pune, Mumbai, Thiruvananthapuram. Most of the IT organizations have established their business centres in these cities and hence South India was chosen for the study. Random sampling technique was adopted and a total of 1220 employees were invited by e-mail to participate in the survey. The questionnaire statements were posted in a google-form at a web-link and the web-link was sent over e-mail to participants. Out of 1220 employees who were invited, 852 employees filled in the questionnaire and submitted.

\subsection{Statistical Analysis}

The underlying dimensions (factors) pertaining to 37 statements were determined by Factor analysis using Principal components analysis with Varimax rotation method. The reliability of the statements was estimated using Cronbach Alpha Coefficient explained by Cronbach (1951). Kaiser-Meyer Olkin (K.M.O) measure of sampling adequacy and Bartlett's test of sphericity was conducted to test the fitness of the data. Relationship between dimensions and WLB was determined by Pearson's correlation analysis. Regression Analysis was used for Hypothesis testing and determining the directions and magnitudes of associations between the factors \& Work-Life Balance.

\section{Results \& Discussion}

A total of 852 respondents participated in the survey. 66.7 percent of the respondents are males and 33.3 percent are females. Most of the respondents are of the age: $21-$ 30 years. More than half of the respondents are married. The social demographic details are presented in Table 1. The mean ratings of the statements in the questionnaire are presented in Table 2. Statement \#35 was rated the highest with mean score: 3.62 and statement \#37 was rated the lowest with mean score 2.08. KMO test and Bartlett's test of sphericity was conducted and resulted in 0.892 and 1525.01 at 0.000 significance level respectively which indicates the sampling adequacy and appropriateness of the responses received. 
Table 1 Demographic Profile of Respondents

\begin{tabular}{|c|c|c|}
\hline Demographic factor & Category & Percent \\
\hline \multirow{2}{*}{ Sex } & Male & 66.7 \\
\hline & Female & 33.3 \\
\hline \multirow{4}{*}{ Age } & $21-30$ & 53.8 \\
\hline & $31-40$ & 35.9 \\
\hline & $41-50$ & 7.7 \\
\hline & $>50$ & 2.6 \\
\hline \multirow{4}{*}{ Marital status } & Married & 52.6 \\
\hline & Single & 43.6 \\
\hline & Divorced & 2.6 \\
\hline & Separated & 1.3 \\
\hline \multirow{4}{*}{ No of dependents } & 0 & 53.8 \\
\hline & 1 & 28.2 \\
\hline & 2 & 16.7 \\
\hline & $>2$ & 1.3 \\
\hline \multirow{3}{*}{ Employment status } & Full time & 100 \\
\hline & Part time & 0 \\
\hline & Casual & 0 \\
\hline \multirow{4}{*}{ Experience } & $0-5$ & 50 \\
\hline & $6-10$ & 41 \\
\hline & $11-20$ & 5.1 \\
\hline & $>20$ & 3.8 \\
\hline \multirow{6}{*}{ Place of Work } & Chennai (120) & 14.08 \\
\hline & Bangalore (204) & 23.94 \\
\hline & Hyderabad (288) & 33.80 \\
\hline & Pune (72) & 8.40 \\
\hline & Mumbai (96) & 11.26 \\
\hline & Trivandrum (72) & 8.40 \\
\hline
\end{tabular}

Table 2 Mean Ratings of the Responses

\begin{tabular}{|ll|c|c|}
\hline \multicolumn{1}{|c|}{ Item } & Mean & SD \\
\hline 1. & My manager is sensitive to my non-work needs & 3.35 & 1.01 \\
\hline 2. & $\begin{array}{l}\text { My manager is sympathetic towards employees' childcare/elder care } \\
\text { responsibilities. }\end{array}$ & 3.54 & 0.90 \\
\hline 3. & $\begin{array}{l}\text { In the event of a conflict, managers are understanding when employees } \\
\text { have to put their non work responsibilities first }\end{array}$ & 3.27 & 1.07 \\
\hline 4. & Employees are allowed to work from home/shifts when required & 3.59 & 1.07 \\
\hline 5. & $\begin{array}{l}\text { The workplace is supportive of employees who want to switch to less demand } \\
\text { ing jobs for family reasons }\end{array}$ & 3.12 & 0.97 \\
\hline 6. & My organization has well laid down work life balance policies & 3.24 & 0.95 \\
\hline 7. & $\begin{array}{l}\text { The work life balance policies are applied the same way at all levels of } \\
\text { management. }\end{array}$ & 3.03 & 1.06 \\
\hline 8. & $\begin{array}{l}\text { In this work environment, employees can easily balance their work and non- } \\
\text { work lives }\end{array}$ & 3.23 & 1.08 \\
\hline 9. & $\begin{array}{l}\text { Employees who avail work life balance policies are perceived to be } \\
\text { less serious about their careers than those who do not participate }\end{array}$ & 3.10 & 1.02 \\
\hline 10. & $\begin{array}{l}\text { Turning down a promotion or transfer for personal reasons will hurt } \\
\text { career progress }\end{array}$ & 3.64 & 0.92 \\
\hline
\end{tabular}


11. Employees who use work life balance policies are less likely to advance in their careers than those who do not use

12. Employees are expected to work overtime

13. Employees are expected to put their jobs before their personal responsibilities to move ahead in their careers

14. Colleagues encourage their team members' use of work-life balance policies

15. If an employee is away from work due to a worklife balance arrangement, colleagues generally resent to help

16. Workloads are not shared equally in this workplace because some employees are not around for part of the week

17. Some employees in this workplace have to do more than their fair share to compensate for the people using work-life policies

18. Flexible work arrangements and policies are available mainly for women in $\mathrm{t}$ his organization

19. Male employees are more reluctant than women to ask for time off to deal with their family and non work responsibilities

20. Men who put their non work responsibilities before their jobs are thought of more negatively than women who do this

21. Work pressure does not allow me to have the personal life I wish

22. Work demands/deadlines make my personal life stressful (ex: becoming irritable at home, spouse feeling uncomfortable etc..)

23. Work commitments would keep me pre-occupied and I am not able to fulfil my family responsibilities (ex: taking care of dependents)/not able to attend social functions

24. Work schedule/pressure is spoiling my health (ex: depression, blood pressure etc.)

25. Work pressure does not allow me to have proper sleep

26. Psychological stress from personal/family life distracts me while at work (ex: worrying about dependent care)

27. Physically tired to discharge my work due to multiple responsibilities at home

28. Pre-occupation with family/social activities makes me postpone work

29. Family obligations/demands interfere with work

30. Personal/ family life support helps me improve motivation, dedication and commitment for work

31. Interactions \& relationships with family members and the experience of managing family issues provide me better soft skills which help my growth in office

32. Family/personal life builds my self-esteem and confidence at work place

33. Work place provides me enough opportunities to fulfil my personal/family obligations (ex: maternity leave, carers' leave, study leave etc.)

34. Work schedule allows me to plan and execute my personal/family responsibilities

35. Work place contributes to the development of my personality

36. Work provides me enthusiasm and happiness to pursue my family/personal roles

37. I have become a better parent/family member because of my work experience

$3.10 \quad 1.11$

The responses received for the statements in the questionnaire were factor analysed using Principal component analysis with Varimax rotation method to determine the factors or dimensions underlying the latent construct WLB. Factor 
analysis resulted in determining the following nine constructs: Manager Support (MS), Organisational Support (OS), Negative Career Consequences (NCC), Coworker Non-Support (CNS), Gender Imbalance (GI), Work Interference into Personal Life (WIPL), Personal Life Interference into Work Life (PIWL), Work Enhancement due to Personal Life (WEPL) and Personal Life Enhancement due to Work Life (PEWL). During the factor analysis, only those factors were considered whose Eigen values were greater than one as given in Hair et al. (1998) and whose factor loadings were greater than 0.4 . The factor loadings and reliability estimates of the constructs along with the Eigen values and their variances are presented in Table 3.

Table 3 Factor Loading Schedule along with Reliability Coefficient of Constructs during Factor Analysis

\begin{tabular}{|c|c|c|c|c|c|c|}
\hline $\begin{array}{c}\text { Item } \\
\text { no. }\end{array}$ & $\begin{array}{l}\text { Factor } \\
\text { Loading }\end{array}$ & Factor name & $\begin{array}{l}\text { Eigen } \\
\text { Value }\end{array}$ & $\begin{array}{l}\text { Variance } \\
\text { (percent) }\end{array}$ & $\begin{array}{l}\text { Cumulative } \\
\text { Variance } \\
\text { (percent) }\end{array}$ & $\begin{array}{l}\text { Cronbach } \\
\text { alpha }\end{array}$ \\
\hline 12 & 0.42 & \multirow{6}{*}{$\begin{array}{l}\text { Work Interference into } \\
\text { Personal Life (WIPL) }\end{array}$} & \multirow{6}{*}{9.79} & \multirow{6}{*}{27.99} & \multirow{6}{*}{27.99} & \multirow{6}{*}{0.864} \\
\hline 13 & 0.42 & & & & & \\
\hline 21 & 0.44 & & & & & \\
\hline 22 & 0.40 & & & & & \\
\hline 23 & 0.52 & & & & & \\
\hline 24 & 0.46 & & & & & \\
\hline 4 & 0.41 & \multirow{5}{*}{$\begin{array}{l}\text { Organizational Support } \\
\text { (OS) }\end{array}$} & \multirow{5}{*}{4.35} & \multirow{5}{*}{12.44} & \multirow{5}{*}{40.43} & \multirow{5}{*}{0.841} \\
\hline 5 & 0.55 & & & & & \\
\hline 6 & 0.74 & & & & & \\
\hline 7 & 0.82 & & & & & \\
\hline 8 & 0.75 & & & & & \\
\hline 33 & 0.84 & \multirow{4}{*}{$\begin{array}{l}\text { Personal life } \\
\text { enhancement due to } \\
\text { work life (PEWL) }\end{array}$} & \multirow{4}{*}{2.99} & \multirow{4}{*}{8.57} & \multirow{4}{*}{49.00} & \multirow{4}{*}{0.846} \\
\hline 34 & 0.82 & & & & & \\
\hline 35 & 0.65 & & & & & \\
\hline 36 & 0.58 & & & & & \\
\hline 1 & 0.80 & \multirow{4}{*}{ Manager Support (MS) } & \multirow{4}{*}{1.71} & \multirow{4}{*}{4.89} & \multirow{4}{*}{53.90} & \multirow{4}{*}{0.813} \\
\hline 2 & 0.64 & & & & & \\
\hline 3 & 0.51 & & & & & \\
\hline 14 & 0.46 & & & & & \\
\hline 26 & 0.75 & \multirow{4}{*}{$\begin{array}{l}\text { Personal Life } \\
\text { Interference into Work } \\
\text { Life (PIWL) }\end{array}$} & \multirow{4}{*}{1.62} & \multirow{4}{*}{4.63} & \multirow{4}{*}{58.52} & \multirow{4}{*}{0.861} \\
\hline 27 & 0.80 & & & & & \\
\hline 28 & 0.85 & & & & & \\
\hline 29 & 0.80 & & & & & \\
\hline 30 & 0.75 & Work life enhancement & 1.58 & 4.54 & 63.06 & 0.905 \\
\hline
\end{tabular}




\begin{tabular}{|c|c|c|c|c|c|c|}
\hline $\begin{array}{l}\text { Item } \\
\text { no. }\end{array}$ & $\begin{array}{l}\text { Factor } \\
\text { Loading }\end{array}$ & Factor name & $\begin{array}{l}\text { Eigen } \\
\text { Value }\end{array}$ & $\begin{array}{l}\text { Variance } \\
\text { (percent) }\end{array}$ & $\begin{array}{l}\text { Cumulative } \\
\text { Variance } \\
\text { (percent) }\end{array}$ & $\begin{array}{l}\text { Cronbach } \\
\text { alpha }\end{array}$ \\
\hline 31 & 0.81 & \multirow{2}{*}{$\begin{array}{l}\text { due to personal life } \\
\text { (WEPL) }\end{array}$} & & & & \\
\hline 32 & 0.86 & & & & & \\
\hline 9 & 0.75 & \multirow{3}{*}{$\begin{array}{l}\text { Negative Career } \\
\text { Consequences (NCC) }\end{array}$} & \multirow{3}{*}{1.25} & \multirow{3}{*}{3.59} & \multirow{3}{*}{63.65} & \multirow{3}{*}{0.862} \\
\hline 10 & 0.25 & & & & & \\
\hline 11 & 0.68 & & & & & \\
\hline 15 & 0.66 & \multirow{3}{*}{$\begin{array}{l}\text { Co-worker } \\
\text { Non-Support (CNS) }\end{array}$} & \multirow{3}{*}{1.16} & \multirow{3}{*}{3.33} & \multirow{3}{*}{69.98} & \multirow{3}{*}{0.895} \\
\hline 16 & 0.67 & & & & & \\
\hline 17 & 0.60 & & & & & \\
\hline 18 & 0.73 & \multirow{3}{*}{ Gender Imbalance (GI) } & \multirow{3}{*}{1.14} & \multirow{3}{*}{3.28} & \multirow{3}{*}{73.26} & \multirow{3}{*}{0.802} \\
\hline 19 & 0.57 & & & & & \\
\hline 20 & 0.45 & & & & & \\
\hline
\end{tabular}

WIPL has the largest Eigen value 9.79 and contributes about 27.99 percent of the variance, making it the most significant dimension of WLC. GI has the lowest Eigen value 1.14 and contributes about 3.28 percent. Construct validity of the questionnaire is established through the factor analysis. The factor analysis resulted in the constructs as agreed upon as in Fisher-McAuley et al. (2003) and Bradley et al. (2010).

Statement 37 was deleted to increase the reliability and statement 25 was removed as its factor loading was less than 0.4. Finally, the second part of the questionnaire consisted of 35 statements only. Statements 12, 13, 21-24 were loaded on to WIPL which has an Eigen value of 9.79 and reliability alpha value of 0.864 . This factor reflects the interference of work into personal lives of respondents. This factor was negatively scored for the measurement of WLB. Statements 4-8 were loaded on to the construct: OS which has Eigen value of 4.35 with a reliability alpha coefficient 0.841 and this factor was positively scored. Statements 33-36 were loaded on to Personal life enhancement into work Life (PEWL) which has an Eigen value of 2.99 and reliability alpha value of 0.846 . This factor corresponds to the well being of the respondent due to satisfactory or productive work life and this factor was positively scored.

Statements 1-3 \& 14 were loaded on to the construct: MS which has Eigen value of 1.71 with a reliability alpha coefficient 0.813 . This factor was positively scored and this factor is reflection of the support the respondent gets from his immediate superior. Statements 26-29 were loaded on to PIWL which has an Eigen value of 1.62 and reliability alpha value of 0.861 . This factor reflects the interference of personal life into work lives of respondents and was negatively scored. Statements 30-32 were loaded on to WEPL which has an Eigen value of 1.58 and reliability alpha value of 0.905 . This factor was positively scored and it corresponds to the improvement in work life due to a satisfied personal life. Statements 9-11, 15-17, 1820 contributed to the constructs: NCC, CNS and GI with Eigen values 1.25, 1.16, 1.14 and reliability alpha coefficients $0.862,0.895,0.802$ respectively. All these constructs were negatively scored in the measurement scale. Based on the existing 
works by Thompson et al. (1999) and Bradley et al. (2010), the constructs: MS, OS, NCC, CNS, GI were proved to be the dimensions of WLC. The sum of the scores of the statements corresponding to these five constructs is taken as the score of WLC. The sum of all the scores of all the 35 statements for each respondent is taken as total score for WLB. The descriptive statistics for WLB and its nine constructs are presented in Table 4.

Table 4 Descriptive Statistics

\begin{tabular}{|l|c|c|c|c|c|c|c|c|c|c|}
\hline & WIPL & OS & PEWL & MS & PIWL & WEPL & NCC & CNS & GI & WLB \\
\hline Mean & 19.0389 & 16.2467 & 13.5064 & 13.4805 & 11.9220 & 10.5844 & 9.89610 & 9.88311 & 9.80519 & 107.2078 \\
\hline Std dev & 5.00266 & 4.03075 & 3.37127 & 3.15586 & 3.34858 & 2.94129 & 2.05087 & 2.21789 & 2.33824 & 17.85359 \\
\hline Skewness & -0.0450 & -0.6156 & -0.4550 & -0.8387 & 0.57771 & -0.8978 & 0.22247 & -0.4629 & -0.11343 & -0.89782 \\
\hline Kurtosis & -0.6233 & 0.53802 & 0.43611 & 1.60094 & 0.02877 & 0.85301 & -0.53914 & 0.37383 & 0.08787 & 2.699646 \\
\hline
\end{tabular}

WLB has a mean score of 107.20 with 17.85 as standard deviation. Among the constructs, WIPL has highest mean score 19.03 with 5.00 as standard deviation and GI has the lowest mean score 9.80 with 2.33 as standard deviation.

\subsection{Hypothesis Testing}

\subsubsection{Correlation Analysis}

Pearson Correlation analysis (using t-test) was done on WLB and its constructs to determine the relationships between them. Table 5 presents the correlation matrix. Correlation analysis revealed that MS, OS, WEPL and PEWL are positively correlated with WLB having correlation coefficients $0.712,0.767,0.390$ and 0.647 respectively.

Table 5 Correlation Matrix (All Calculations at 0.05 Significant Level)

\begin{tabular}{|l|c|c|c|c|c|c|c|c|c|c|}
\hline & MS & OS & NCC & CNS & GI & WIPL & PIWL & WEPL & PEWL & WLB \\
\hline MS & 1 & 0.648553 & -0.21146 & -0.40662 & -0.27831 & -0.50736 & -0.03832 & 0.189818 & 0.460284 & 0.712929 \\
\hline OS & 0.648553 & 1 & -0.29446 & -0.45828 & -0.22827 & -0.58655 & -0.04004 & 0.230425 & 0.462973 & 0.767571 \\
\hline NCC & -0.21146 & -0.29446 & 1 & 0.237677 & 0.24275 & 0.406333 & 0.180755 & 0.10718 & -0.12602 & -0.43591 \\
\hline CNS & -0.40662 & -0.45828 & 0.237677 & 1 & 0.168768 & 0.569329 & 0.217829 & -0.31471 & -0.40112 & -0.68536 \\
\hline GI & -0.27831 & -0.22827 & 0.24275 & 0.168768 & 1 & 0.263236 & 0.367079 & 0.228543 & 0.009242 & -0.38562 \\
\hline WIPL & -0.50736 & -0.58655 & 0.406333 & 0.569329 & 0.263236 & 1 & 0.481108 & -0.08204 & -0.33378 & -0.82823 \\
\hline PIWL & -0.03832 & -0.04004 & 0.180755 & 0.217829 & 0.367079 & 0.481108 & 1 & 0.003312 & -0.04492 & -0.44537 \\
\hline WEPL & 0.189818 & 0.230425 & 0.10718 & -0.31471 & 0.228543 & -0.08204 & 0.003312 & 1 & 0.592236 & 0.39077 \\
\hline PEWL & 0.460284 & 0.462973 & -0.12602 & -0.40112 & 0.009242 & -0.33378 & -0.04492 & 0.592236 & 1 & 0.647609 \\
\hline WLB & 0.712929 & 0.767571 & -0.43591 & -0.68536 & -0.38562 & -0.82823 & -0.44537 & 0.39077 & 0.647609 & 1 \\
\hline
\end{tabular}


Rest of the constructs WIPL, PIWL, NCC, CNS and GI are negatively correlated with WLB with correlation coefficients $-0.828,-0.445,-0.435,-0.685$ and -0.385 , respectively. The t-values and the corresponding p-values obtained for two tailed tests at 0.05 significance level are presented in Table 6 .

Table 6 Pearson Correlation Analysis (using T-Test and all Calculations at 0.05 Significant Level-Two Tailed)

\begin{tabular}{|l|c|c|c|c|c|c|c|c|c|c|}
\hline & $\begin{array}{c}\text { WLB \& } \\
\text { WIPL }\end{array}$ & WLB \& & WLB \& & WLB \& & WLB \& & WLB\& & WLB \& & WLB \& & WLB \& & WLB \& \\
PEWL & MS & OS & NCC & CNS & GI & WLC \\
\hline Alpha & 0.05 & 0.05 & 0.05 & 0.05 & 0.05 & 0.05 & 0.05 & 0.05 & 0.05 & 0.05 \\
\hline Tails & 2 & 2 & 2 & 2 & 2 & 2 & 2 & 2 & 2 & 2 \\
\hline $\begin{array}{l}\text { Corr } \\
\text { Coeff }\end{array}$ & -2.8282 & -0.4453 & 0.3907 & 0.6476 & 0.78842 & 0.8359 & -0.5409 & -0.6519 & -0.6675 & 0.9146 \\
\hline Std err & 0.0261 & 0.0417 & 0.0429 & 0.0355 & 0.0286 & 0.0255 & 0.0392 & 0.0353 & 0.0347 & 0.0188 \\
\hline T & -31.691 & -10.6685 & 9.1050 & 18.2286 & 27.4900 & 32.6735 & -13.7939 & -18.4416 & -19.2306 & 48.5171 \\
\hline P & $9 \mathrm{E}-116$ & $6.8 \mathrm{E}-24$ & $2.6 \mathrm{E}-118$ & $2.8 \mathrm{E}-56$ & $4 \mathrm{E}-99$ & $6 \mathrm{E}-122$ & $1.8 \mathrm{E}-36$ & $2.9 \mathrm{E}-57$ & $6.5 \mathrm{E}-61$ & $5 \mathrm{E}-183$ \\
\hline
\end{tabular}

From Table 6, it is clearly evident that there exists a positive relationship between WLB and WLC (last column). PEWL and WEPL are also positively correlated with WLB. A negative relationship exists between WLB and WIPL \& PIWL as well.

\subsubsection{Regression Analysis}

WLB is taken as the dependent variable and WLC (which is the sum of its factors: MS, OS, NCC, CNS, GI), WIPL, PIWL, PEWL, WEPL are taken as independent variables for performing the linear regression analysis. The multiple regression coefficient $\mathrm{R}$ is 0.997794 and the coefficient of determination $\mathrm{R}^{2}$ is 0.995593 indicates that 99.55 percent of the variance of the latent construct WLB is explained by its nine factors proving that this regression model is a good fit. ANOVA results are presented in Table 7 and the F-value is found to be 865.825 with $p<0.05$. The regression beta coefficients are presented in Table 7 .

Table 7 ANOVA Results

\begin{tabular}{|l|c|c|c|c|c|c|}
\hline ANOVA & & & & Alpha & $\mathbf{0 . 0 5}$ & \\
\hline & $\boldsymbol{D} \boldsymbol{f}$ & $\boldsymbol{S S}$ & $\boldsymbol{M S}$ & $\boldsymbol{F}$ & $\boldsymbol{p}$-Value & Sig \\
\hline Regression & 5 & 122922.5 & 24584.5 & 865.825 & 0 & Yes \\
\hline Residual & 846 & 24021.6 & 28.3943 & & & \\
\hline Total & 851 & 146944.1 & & & & \\
\hline
\end{tabular}

Table 8 Regression Coefficients

\begin{tabular}{|l|c|c|c|c|}
\hline & Coeff & Std Err & t Stat & p-Value \\
\hline Intercept & 48.57899 & 0.761518 & 63.79234 & $2.2 \mathrm{E}-229$ \\
\hline WLC & 1.000786 & 0.008573 & 116.7327 & 0 \\
\hline WIPL & -0.69379 & 0.019378 & -35.8026 & $1.4 \mathrm{E}-134$ \\
\hline PIWL & -1.06629 & 0.019451 & -54.8201 & $8 \mathrm{E}-203$ \\
\hline WEPL & 1.043597 & 0.023813 & 43.82519 & $1.4 \mathrm{E}-165$ \\
\hline PEWL & 1.019443 & 0.023198 & 43.94497 & $5.1 \mathrm{E}-166$ \\
\hline
\end{tabular}


To Test the Null Hypothesis $\mathrm{H}_{10}$

From Table 6 , it is evident that WLB is positively correlated with WLC (0.9146) and the $p$-value from the correlation analysis using t-test was less than 0.05 alpha value. From Table 8, it is clear from regression analysis that WLC is significant positive predictor of WLB with beta coefficient 1.0007 respectively and $\mathrm{p}<0.05$ and hence from the above results, $\mathrm{H}_{10}$ may comfortably be rejected and alternate hypothesis $\mathrm{H}_{1 \mathrm{a}}$ is accepted.

\section{To Test the Null Hypothesis $\mathbf{H}_{20}$}

From Table 6, it is evident that WLB is negatively correlated to WIPL $(-0.8282) \&$ PIWL (-0.4453) and the p-value from the correlation analysis using t-test was less than 0.05 alpha value. From Table 8 , it is clear from regression analysis that WIPL and PIWL are significant negative predictors of WLB with beta coefficients -0.693 and -1.066 respectively and $\mathrm{p}<0.05$ and hence from these results, $\mathrm{H}_{20}$ may comfortably be rejected and alternate hypothesis $\mathrm{H}_{2 \mathrm{a}}$ is accepted.

\section{To Test the Null Hypothesis $\mathbf{H}_{30}$}

From Table 6, it is evident that WLB is positively correlated to WEPL (0.3907) \& PEWL (0.6476) and the p-value from the correlation analysis using t-test was less than 0.05 alpha value. From Table -8 , it is clear from regression analysis that WEPL and PEWL are significant positive predictors of WLB with beta coefficients 1.043 and 1.019 respectively and $\mathrm{p}<0.05$ and hence from these results, $\mathrm{H}_{30}$ may comfortably be rejected and alternate hypothesis $\mathrm{H}_{3 \mathrm{a}}$ is accepted.

\section{Conclusion}

The present study developed a 35 statement instrument to evaluate the extended measure of WLB among the IT employees belonging to various organizations of South India. The measurement scale is developed for WLB taking into consideration a new dimension: cultural aspects, prevailing in the IT organizations, which was not the case in earlier works on WLB. The measured WLB has a mean score of only 107.20 whereas the maximum score a participant can get for the 35 statement questionnaire is 175 .

The major finding of the current study from the quantitative analysis is the positive correlation of WLC with WLB which implies that the employee satisfaction and commitment towards the organization could be increased with family friendly policies and organisational support. Correlation analysis reveals the extent of the association of the factors with WLB on which the organization should concentrate or work towards increasing the WLB. Regression analysis reiterates the factors significantly contributing to WLB. This study enables organizations to utilise the developed scale and find the WLB score of their employees and identify the factors that affect the WLB of their staff. WIPL with a dominant mean score of 19.03 indicates that most of the respondents feel the interference of work in personal lives. Even though there seems to be good organizational support with mean score of 16.24 , it is clearly evident from the study that the organizations have to focus on mitigating the interference of work into personal life.

All the respondents participated in the survey were assumed to have neutral mindset and unbiased approach towards answering the questionnaire. The respondents are from different organizations spread across South India and the 
conditions/policies prevailing in those organizations are considered by the respondents while giving their responses. Thus the results obtained from quantitative analysis are deemed to reflect the general trend of IT sector in South India. The earlier studies broadly studied WIPL, PIWL, WEPL and PEWL whereas this work identifies other factors like OS, MS, NCC, CNS, GI faced at work place. More importantly, the employee perceptions of negative factors like NCC, CNS and GI were brought out.

The present study augments the existing literature on WLB by adding WLC as an additional dimension and has a very good agreement with the ideas and results generated from previous studies on WLB.

\section{References}

1. Allen, T. D. \& Russell, J. E., 'Parental leave of absence: Some not so family friendly implications', Journal of Applied Social Psychology, 29(1), 1999, 166191.

2. Allen, T.D., 'Family-supportive work environments: The role of organizational perceptions', Journal of Vocational Behaviour, 58, 2001, 414-435.

3. Baltes, B., Briggs, T., Huff, J. \& Wright, J., 'Flexible and compressed workweek schedules: A meta-analysis of their effects on work-related criteria', Journal of Applied Psychology, 84, 1999, 496-513.

4. Edvardsson, B. \& Gustavsson, B., 'Quality in the work environment: a prerequisite for success in new service development', Managing Service Quality, 13(2), 2003, 148-163.

5. Behson, S.J., 'Which dominates? The relative importance of work-family organizational support and general organizational context on employee outcomes', Journal of Vocational Behaviour, 61, 2002, 53-72.

6. Bradley, Lisa, M., McDonald, Paula, K.Brown, Kerry A., 'An extended measure of work

life balance culture: development and confirmation of the measure', In Proceedi ngs of Annual Meeting of the Academy of Management, 6-10 August 2010, Montréal.

7. Clark, S. C., 'Work/family border theory: A new theory of work/family balance', Human Relations, 53, 2000, 747-770.

8. Cronbach, L.J., 'Coefficient alpha and internal structure tests', Psychometrika, $16,1951,297-334$.

9. Fisher, G., 'Work/personal life balance: A construct development study', Unpublished Doctoral dissertation. Bowling Green State University Bowling Green, Ohio, USA, 2001.

10. Fisher-McAuley, G., Stanton, J., Jolton, J., \& Gavin, J. , 'Modelling the relationship between work life balance and organisational outcomes', Paper presented at the Annual Conference of the Society for Industrial-Organisational Psychology, Orlando, 2003, 1-26.

11. Frone, M. R., Yardley, J. K. \& Markel, K. S., 'Developing and testing an integrative model of the work-family interface' Journal of Vocational Behaviour, 50, 1997, 145-167.

12. Greenhaus, J.H. \& Beutell, N.J., 'Sources of conflict between work and family roles', Academy of Management Review, 10, 1985, 76-88. 
13. Greenhaus, J. \& Parasuraman, S., 'Work-family conflict, social support and well-being', in Davidson, M. and Burke, R. (Eds.) Women in management: Current research issues, London: Paul Chapman, 1994.

14. Greenhaus, J. H., Collins, K. M., Singh, R. \& Parasuraman, S., 'Work and family influences departure from public accounting', Journal of Vocational Behaviour, 50, 1997, 249-270.

15. Greenhaus, J. H., Parasuraman, S. \& Collins, K. M., 'Career involvement and family involvement as moderators of relationships between work-family conflict and withdrawal from a profession', Journal of Occupational Health Psychology, 6, 2001, 91-100.

16. Greenhaus, J.H., \& Powell, G.H., 'When work and family are allies: A theory of work family enrichment', Academy of Management Review, 31(1), 2003, 72-92.

17. Hair, J., Anderson, R.E., Tatham, R.L. \& Black, W.C., 'Multivariance data analysis', 5 ed., New Jersey: Prentice Hall, 1998.

18. Hall, D. T., 'Promoting work/family balance: An organization-change approach', Organizational Dynamics, 18(3), 1990, 5-18.

19. Hayman, J., 'Psychometric assessment of an instrument designed to measure work life balance', Research and Practice in Human Resource Management, 13, 2005, 85-89.

20. Jefrey, Greenhaus, H., Karen, Collins, M. \& Jason, Shaw, D., 'The relation between work-family balance and quality of life', Journal of Vocational behaviour, 63, 2003, 510-531

21. Jyothi, Sree. V \& Jyothi, P., 'Assessing Work-Life Balance: From Emotional Intelligence and Role Efficacy of Career Women', Advances in Management, Vol 5 (6), 2012, 35-43.

22. Kirchmeyer, C., 'Work-life initiatives: Greed or benevolence regarding workers time', In C. L.Cooper \& D. M. Rousseau (Eds.), Trends in organizational behaviour, Vol. 7, 2000, 79-93. West Sussex, UK: Wiley.

23. Kofodimos, J. R., 'Balancing act', San Francisco: Jossey-Bass, 1993.

24. Konrad, A. \& Mangel, R., 'The impact of work-life programs on firm productivity', Strategic Management Journal, 21, 2000, 1225-1237.

25. Marshall, N.L. \& Barnett, RC., 'Work-family strains and gains among twoearner couples', Journal of Community Psychology, 21,1993, 64-78.

26. Marks, S. R. \& MacDermid, S. M., 'Multiple roles and the self: A theory of role balance', Journal of Marriage and the Family, 58, 1996, 417-432.

27. Mathew, Rincy, V \& Panchanatham, N., 'An empirical analysis of the impact of various dimensions of work-life balance on organizational commitment among service sector employees in India', International Journal of Management Studies (IJMS), 17 (1), 2010, 129-147. ISSN 0127-8983

28. Mathew, Rincy, V. \& Panchanatham, N., 'Development Of A Psychometric Instrument To Measure Work Life Balance', Continental J. Social Sciences, 3,2010, 50 - 58, ISSN: 2141 - 4265

29. McDonald, P., Brown, K. \& Bradley, L., 'Explanations for the provisionutilisation gap in work-life policy', Women in Management Review, 20(1), 2005, 37-55. 
30. Milind, Peshave, A. \& Rajashree, Gujarathi, 'An Analysis of Work-Life Balance (WLB) Situation of Employees and its Impact on Employee Productivity with Special Reference to the Indian Hotel Industry', Asian Journal of Management 5(1), 2014, 69-74. ISSN- 0976- 495X

31. Netemeyer, R. G., Boles, J. S. \& McMurrian, R., 'Development and validation of work-family conflict and family-work conflict scales', Journal of Applied Psychology, 81, 1996, 400-410.

32. Payton-Miyazaki, M., \& Brayfield, A.H., 'The good job and the good life: Retention of characteristics of employment to general well being', In. A.D. Biderman \& T.F. Drusy (Eds.), Measuring Work Quality for Social Reporting, (10-5-150), Beverly Hills: Sage, 1976.

33. Perry-Smith, J. \& Blum, T., 'Work-family human resource bundles and perceived organizational performance', Academy of Management Journal, 43, 2000, 1107-1117.

34. Gropel, P. \& Kuhl, J., 'Work-Life Balance and Subjective Well-Being: The Mediating Role of Need Fulfilment', British Journal of Psychology, 100(2), 2009, 365-375.

35. Rincy, Mathew, V. \& Panchanatham, N., 'An Exploratory Study on the WorkLife Balance of Women Entrepreneurs in South India', Asian Academy of Management Journal, Vol. 16, No. 2, 2011, 77-105.

36. Rothausen, T. J., 'Job satisfaction and the parent worker: The role of flexibility and rewards', Journal of Vocational Behaviour, 44, 1994, 317-336.

37. Solomon, C. M., 'Work/family's failing grade: Why today's initiatives aren't enough', Personnel Journal, 73, 1994, 72-87.

38. Thiede, T. L. \& Ganster, D. C., 'Impact of family-supportive work variables on work', Journal of Applied Psychology, 80, 1995, 6-15.

39. Thompson, C., Beauvais, L. \& Lyness, K., 'When work-family benefits are not enough: The influence of work-family culture on benefit utilization, organizational attachment, and work-family conflict', Journal of Vocational Behaviour, 54, 1999, 392-415.

40. Zedeck, K.S., 'Introduction: Exploring the domain of work and family concerns', In: Zedeck (Ed.), Work Families and Organisations, San Francisco, 1999.

41. Ashwini, J. \& Anand, D., 'Quality of Work Life Evaluation among Service Sector Employees', IOSR Journal of Business and Management, ISSN: 23197668, 16, Issue 9, Ver. I, Sep, 2014, pp 01-12.

42. Rashida Banu, A. \& Duraipandian, K, 'Development of an instrument to measure Work Life Balance of IT professionals in Chennai', International Journal of Management, ISSN 0976 - 6502, 5, Issue 11, Nov, 2014, pp 21-33.

43. Chandrasekar, K.S., Suma, S.R., Renjini, Nair, S. \& Anu, S.R., 'Study on work life balance among the executives in it industry with special reference to technopark, Trivandrum, Kerala', Asian Journal of Multidimensional Research, 2, Issue 3, Mar 2013, ISSN 2278-4853, pp 21-33.

44. Sussanna, Shagvaliyeva \& Rashad, Yazdanifard, 'Impact of flexible working hours on Work-Life Balance', American Journal of Industrial and Business Management, 2014, 4, 20-23. 
45. Susi, S. \& Jawaharrani, K., 'Work-Life Balance: The key driver of employee engagement', Asian Journal of Management Research, 2, Issue 1, 2011, ISSN 2229 - 3795, pp 474- 483.

\section{About Our Authors}

Vidyavathi $\mathbf{M}$ is a $\mathrm{PhD}$ Research Scholar at the department of Business Management, University College of Commerce and Business Management, Osmania University, Hyderabad, India. She is a member of All India Management Association (AIMA) and holds a bachelor's degree in Engineering from Osmania University and Master's degree in Business Administration from Jawaharlal Nehru Technological University, Hyderabad. She is the corresponding author for the research article. Her email is: vidyavathim1002@gmail.com.

Surendra Prasad holds a doctorate in Human Resource Management and is currently working as Principal of David Memorial PG College, Tarnaka, Hyderabad, India. His research interests lie in the area of Human Resource Management and Organisational Behaviour. 